\title{
Anti-vascular Endothelial Growth Factor Pharmacotherapy in the Treatment of Subretinal Choroidal Neovascularization
}

\author{
Yoreh Barak, MD, ${ }^{1}$ Mark A Ihnen, $\mathrm{MD}^{2}$ and Shlomit Schaal, MD, $\mathrm{PhD}^{3}$ \\ 1. Vitreo-Retinal Fellow; 2. Ophthalmology Resident; 3. Vitreo-Retinal Specialist, Director, Diabetic Retinopathy Service, and \\ Assistant Professor, Department of Ophthalmology and Visual Sciences, University of Louisville, Kentucky, US
}

\begin{abstract}
Vascular endothelial growth factor (VEGF) plays a pivotal role in stimulating the growth of pathologic subretinal choroidal neovascularization (CNV). The increased production of VEGF and subsequent CNV formation can occur in degenerative, inflammatory, and vascular diseases of the retina and choroid, often leading to severe visual impairment. Anti-VEGF agents which are readily available today are much better, more potent, and longer acting in comparison with previous treatment modalities, and therefore have dramatically improved the prognosis of patients with CNV. There are four intravitreal anti-VEGF pharmacotherapies proven by large prospective, multicenter, randomized trials to be effective in the treatment of age-related macular degeneration (AMD)-related CNV: pegaptanib (Macugen ${ }^{\circledR}$, Eyetech Pharmaceuticals, Palm Beach Gardens, FL), ranibizumab (Lucentis ${ }^{\circledR}$, Genentech, Inc., South San Francisco, CA), bevacizumab (Avastin ${ }^{\circledR}$, Genentech, Inc., South San Francisco, CA), and VEGF Trap-Eye (Eylea ${ }^{\circledR}$ Regeneron, Tarrytown, NY). However, there are still many challenges and unanswered questions regarding the optimal anti-VEGF pharmacotherapy agent, the best clinical treatment regimen, the most effective dosage, the optimal injection frequency, and the duration of treatment. The heavy burden of frequent injections on the elderly patient population and physicians begs for a simpler way of drug administration or development of more potent compounds.
\end{abstract}

\section{Keywords}

Vascular endothelial growth factor, subretinal choroidal neovascularization, age-related macular degeneration, pegaptanib, ranibizumab, bevacizumab, VEGF Trap-Eye

Disclosure: The authors have no conflicts of interest to declare.

Received: October 29, 2011 Accepted: November 21, 2011 Citation: US Ophthalmic Review, 2012:5(2):107-10 DOI: 10.17925/USOR.2012.05.02.107

Correspondence: Shlomit Schaal, MD, PhD, 301 E Muhammad Ali Boulevard, Louisville, KY 40202, US. E: s.schaal@louisville.edu

Intravitreal anti-vascular endothelial growth factor (VEGF) pharmacotherapy, introduced in 2004, ${ }^{1}$ has evolved over the last decade to revolutionize the treatment of patients suffering from subretinal choroidal neovascularization (CNV). Anti-VEGF agents, which are readily available today, are much better, more potent, and longer acting in comparison with previous treatment modalities, and therefore have dramatically improved the prognosis of patients with CNV.

Patients losing vision secondary to CNV, such as patients suffering from exudative age-related macular degeneration (AMD), can now expect stabilization and even improvement of their visual acuity, as opposed to the slow and certain visual deterioration that was the rule before the anti-VEGF era. ${ }^{2-6}$

\section{Vascular Endothelial Growth Factor}

VEGF is a diffusible cytokine that promotes angiogenesis and increases vascular permeability. It is a product of a gene family that plays an important role in normal development and angiogenesis. ${ }^{7}$ The influence of VEGF in retinal diseases is profound. This dimeric glycoprotein of approximately $40 \mathrm{kDa}$ is upregulated in response to hypoxia. It plays a pivotal role in stimulating abnormal growth of pathological new blood vessels in the adult retina and choroid. VEGF is also a potent inducer of vascular permeability and leakage that can lead to retinal edema and thickening.,9

There is mounting evidence that increased VEGF expression is associated with pathologic CNV.? CNV, a form of abnormal blood vessel growth which emerges from choroidal vessels, penetrates Bruch's membrane and grows below the retinal pigment epithelium (RPE) space and into the subretinal space. ${ }^{10}$ Figure 1 shows the different stages of growth of a subretinal choroidal membrane in response to VEGF stimulation.

The increased production of VEGF and subsequent CNV formation can occur in degenerative, inflammatory, neoplastic, traumatic, hereditary, and idiopathic diseases of the retina and choroid. The most commonly encountered conditions associated with $\mathrm{CNV}$ are AMD and pathologic myopia. AMD is the leading cause of irreversible vision loss among the elderly population in the Western world. ${ }^{11}$ All subtypes of exudative AMD, such as retinal angiomatous proliferation, CNV, and polypoidal choroidal vasculopathy, are driven by VEGF, although they differ in anatomical location and clinical behavior ${ }^{7}$ and respond differently to anti-VEGF 
Figure 1: Developmental Stages of a Subretinal Choroidal Membrane

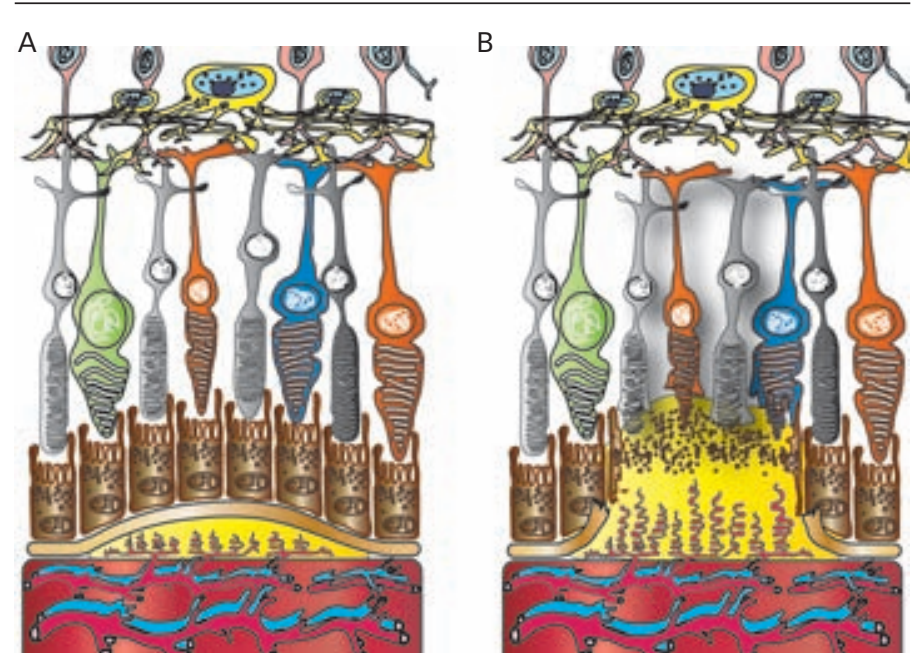

A: Abnormal blood vessels originating from choroidal vessels proliferate; $B$ : the abnormal neovascularization penetrates Bruch's membrane and extends into the subretinal pigmented epithelial and subretinal spaces.

Figure 2: Schematic Structure and Size of the Different Anti-vascular Endothelial Growth Factor Agents

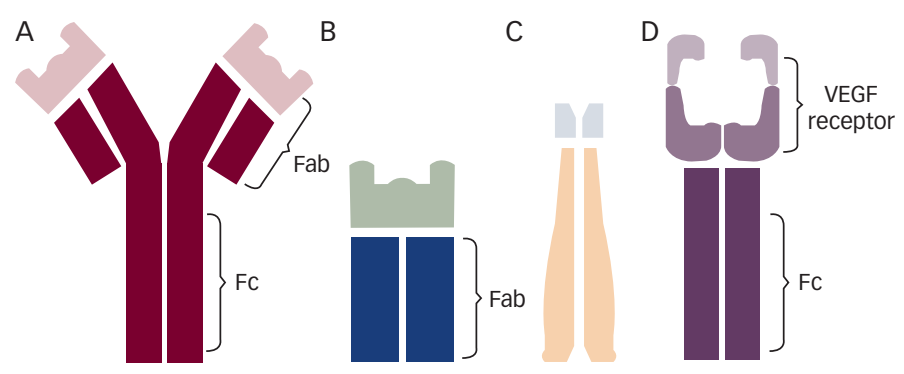

(A) bevacizumab (Avastin ${ }^{\circledR}$ ) 149 kDa; (B) ranibizumab (Lucentis ${ }^{\circledR}$ ) 48 kDa; (C) pegaptanib (Macugen ${ }^{\circledR}$ ) 50 kDa; (D) VEGF Trap-Eye 115 kDa. Fab = antigen-binding fragment; $F C=$ crystallizable fragment; $V E G F=$ vascular endothelial growth factor.

therapy. ${ }^{7,12}$ Pathologic myopia affects nearly $2 \%$ of the worldwide population and one in 10 highly myopic eyes will develop myopic maculopathy. ${ }^{13}$ VEGF plays an important role in the pathogenesis of uveitic-related CNV which is an established complication of posterior uveitis and accounts for $2 \%$ of severe visual loss. ${ }^{14}$ There are favorable reports that CNV secondary to hereditary diseases, such as Best disease, Paget's bone disease, and pseudoxanthoma elasticum, and idiopathic CNV respond well to anti-VEGF pharmacotherapy. ${ }^{15}$ Intravitreal bevacizumab results in a better functional and anatomical outcome compared with thermal laser in patients with juxtafoveal CNV secondary to presumed ocular histoplasmosis syndrome (POHS), a common cause of $\mathrm{CNV}$ in states containing the Mississippi and Ohio river valleys. ${ }^{16}$

\section{Previous Treatments}

Prior to the introduction of anti-VEGF pharmacotherapy, the most common treatment for CNV was photodynamic therapy (PDT) with verteporfin (VisudyneTM, Novartis, Basel, switzerland), which offered, at best, slower but certain visual loss. ${ }^{17}$ Additional treatment modalities included laser photocoagulation which was only applicable to extrafoveal CNV, with $24 \%$ of patients in the treatment group experiencing visual loss of more than six lines compared with $41 \%$ in the observation group. ${ }^{2,18}$ Submacular surgery with CNV removal was not proven to be superior to the less invasive treatment modality of laser photocoagulation of subfoveal CNV and thus this approach was abandoned later on. ${ }^{18,19}$ All of the above treatments are destructive and non-curative in nature. Although anti-VEGF pharmacotherapy is not curative, it can promote regression of the abnormal capillary vasculature and reduces the vascular permeability and leakage, thus potentially restoring the normal retinal architecture and function.

\section{Anti-vascular Endothelial Growth Factor Pharmacotherapies}

To date there are four intravitreal anti-VEGF pharmacotherapies proven by large prospective, multicenter, randomized trials to be effective in the treatment of AMD-related CNV. Many smaller trials have demonstrated anti-VEGF pharmacotherapy to be an effective treatment for CNV secondary to other degenerative and inflammatory conditions. . $^{13,19-21}$ Figure 2 shows the schematic structure and size of the different anti-VEGF agents available today.

The first intravitreal anti-VEGF pharmacotherapy introduced was an oligoribonucleotide aptamer, pegaptanib (Macugen ${ }^{\circledR}$, Eyetech Pharmaceuticals, Pfizer, New York, US). Injected every six weeks, it specifically binds and blocks the activity of extracellular VEGF165 isoform. Pegaptanib was shown to have a smaller proportion of patients who lost fewer than 15 letters of visual acuity at 54 weeks compared with sham injection. ${ }^{1}$ It is important to note that over $50 \%$ of the treated groups lost more than 15 letters and only $33 \%$ maintained or gained visual acuity. ${ }^{1,22}$ A meaningful breakthrough was achieved with ranibizumab (Lucentis ${ }^{\circledR}$, Genentech, Inc., South San Francisco, CA) - a recombinant, humanized, monoclonal antibody antigen-binding fragment (Fab) that neutralizes all active forms of VEGF-A. Monthly intravitreal injections of ranibizumab over the course of 24 months were compared with verteporfin and sham injection in two large studies (Minimally classic/occult trial of the anti-VEGF antibody ranibizumab in the treatment of neovascular AMD [MARINA] $]^{4,6}$ and Anti-vascular endothelial growth factor antibody for the treatment of predominantly classic choroidal neovascularization in age-related macular degeneration [ANCHOR] $)^{4}$ and were found to be effective in the treatment of all forms of AMD-related CNV. In both studies, $90 \%$ of patients receiving ranibizumab lost fewer than 15 letters and 25-41\% gained more than 15 letters, compared with 3.8 and $6 \%$ in the sham-injection and verteporfin groups, respectively.,6 Mean increases in visual acuity were 5.4-10.7 letters in the ranibizumab groups, compared with a decrease of 14.9 and 9.8 in the sham-injection and verteporfin studies, respectively. ${ }^{4-6,23,24}$ A large number of uncontrolled studies yielded similar positive results for bevacizumab (Avastin ${ }^{\circledR}$, Genentech, Inc., South San Francisco, CA), the humanized full-size anti-VEGF antibody, demonstrating its therapeutic effect on subretinal CNV after intravitreal injection. These results, in combination with the more affordable cost of bevacizumab, led to widespread off-label use in the treatment of $\mathrm{CNV}^{21,23,25-27}$ To date, most intravitreal anti-VEGF injections given in the US involve bevacizumab..$^{24,28}$ The one-year results of the Comparison of age-related macular degeneration treatments trials (CATT), a multicenter, single-blind, non-inferiority trial, provided the final evidence that bevacizumab and ranibizumab have equivalent effects on visual acuity when administered according to the same 
schedule. ${ }^{25,29}$ In the CATT study, patients received intravitreal injections of ranibizumab or bevacizumab on either a monthly schedule or as needed, with monthly evaluation. Bevacizumab administered monthly was equivalent to ranibizumab administered monthly, with 8.0 and 8.5 letters gained, respectively. Bevacizumab administered as needed was equivalent to ranibizumab as needed, with 5.9 and 6.8 letters gained, respectively. ${ }^{25,29}$ VEGF Trap-Eye, the most recent anti-VEGF pharmacotherapy introduced into clinical practice, consists of VEGF receptors 1 and 2 fused to the crystallizable fragment $(\mathrm{FC})$ portion of a human immunoglobulin $\mathrm{G}$ that binds both VEGF-A with high affinity and placental growth factor (PIGF), another molecule involved in pathologic angiogenesis and subsequent CNV formation. ${ }^{26,30}$ Results from two phase III, two-year, identical, randomized, double-masked, non-inferiority trials (VEGF Trap-Eye: investigation of efficacy and safety in wet age-related macular degeneration [VIEW-127,31 and VIEW-2]), ${ }^{27,31}$ designed to compare VEGF Trap-Eye with ranibizumab for the treatment of neovascular AMD, are now available. VEGF Trap-Eye was administered at doses of $0.5 \mathrm{mg}$ or $2.0 \mathrm{mg}$ at four-week dosing intervals or $2.0 \mathrm{mg}$ at eight-week dosing intervals, while ranibizumab was administered at $.5 \mathrm{mg}$ every four weeks. The primary endpoint was the proportion of subjects treated with VEGF Trap-Eye who maintained or improved vision at the end of one year, compared with ranibizumab. In VIEW-1 (US), 96, 95, and $95 \%$ of subjects who received VEGF Trap-Eye $0.5 \mathrm{mg}$ monthly, $2 \mathrm{mg}$ monthly, and $2 \mathrm{mg}$ every two months, respectively, achieved maintenance of vision, compared with $94 \%$ of subjects receiving ranibizumab. ${ }^{27,31}$ In VIEW-2 (Europe and Asia) $96 \%$ of subjects in all VEGF Trap-Eye dose groups achieved maintenance of vision, compared with $94 \%$ of subjects receiving ranibizumab. ${ }^{27,31}$ The visual acuity and anatomical outcomes in VIEW-1 and VIEW-2 suggest that VEGF Trap-Eye has the potential to provide outstanding results, similar to those of ranibizumab. VEGF Trap-Eye recently received a unanimous recommendation for approval for the treatment of wet AMD from the Food and Drug Administration (FDA) advisory committee. ${ }^{28,32}$

\section{Treatment Regimen}

In the MARINA and ANCHOR studies, which launched the era of widely used intravitreal injections, ranibizumab was administered on a monthly basis. ${ }^{4-6,23,24}$ Monthly injections are time-consuming for the patient population and treating physician while placing a significant financial burden on the medical system, with an average cost of $\$ 50$ and $\$ 2,067$ per injection of bevacizumab and ranibizumab, respectively. ${ }^{29,33}$ Frequent intravitreal injections also carry a risk of infection, inflammation, and retinal detachment. ${ }^{30,34}$ These important considerations prompted the exploration of newer drug regimens that preserve the therapeutic effect with less frequent injections.

The Phase IIIb, multicenter, randomized, double-masked, sham injection-controlled study of the efficacy and safety of ranibizumab in subjects with subfoveal CNV with or without classic CNV secondary to age-related macular degeneration (PIER) was the first to investigate a less frequent ranibizumab injection schedule. ${ }^{31,35}$ Patients with subfoveal CNV were randomly assigned to receive three monthly injections of ranibizumab followed by quarterly injections on a fixed schedule for one year, for a total of six injections. Patients gained an average of one line of vision at three months, followed by gradual decline over the next nine months. Visual acuity returned to baseline (-0.2 letters) at 12 months..$^{31,35}$ These results led to the conclusion that quarterly injections are inadequate to maintain the visual gain achieved during the first three
Figure 3: The Four Treatment Regimens Commonly Used in Retina Practices

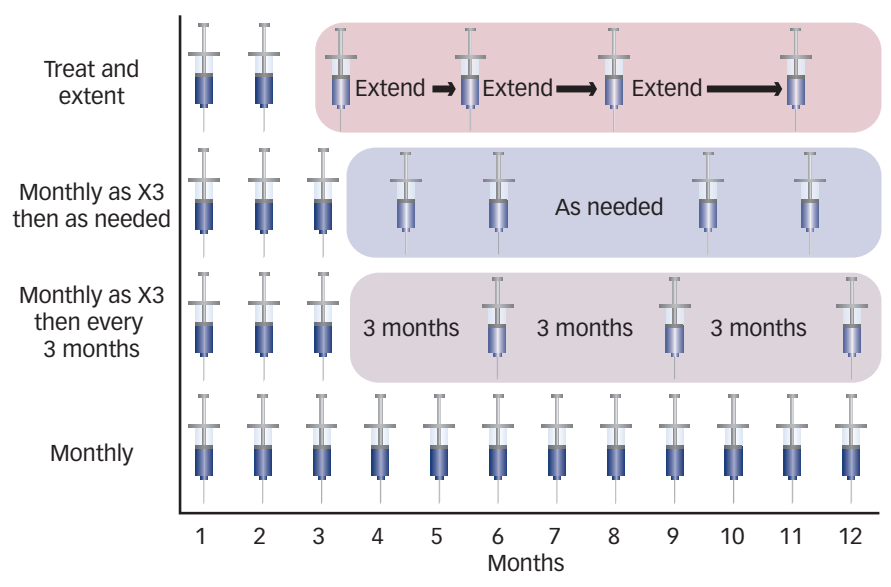

From top: Treat-and-extend method; Monthly for three months then as needed based on optical coherence tomography; Monthly for three months then every three months thereafter; Monthly.

months of therapy with monthly injections. Subset analysis showed that about $70 \%$ of patients treated with ranibizumab gained an average of 10 letters at three months. Of these, $40 \%$ maintained their visual gain, while $60 \%$ experienced visual decline in the next nine months. ${ }^{31,35}$ Thus there is individual variability in response to ranibizumab injections and it may be possible to tailor treatment based on individual characteristics.

The Prospective OCT study with Lucentis for neovascular AMD (PrONTO) was a small, well-designed, open-label trial initiated to explore the use of optical coherence tomography (OCT) as the basis for a less frequent variable dosing regimen with ranibizumab. ${ }^{32,36}$ Each patient received three initial consecutive monthly injections of ranibizumab $(0.5 \mathrm{mg})$ and was followed up monthly thereafter. Re-treatment with ranibizumab was performed on an as-needed basis depending on OCT or fluorescein imaging and clinical examination. ${ }^{32,36}$ At one year there was a mean 10-letter gain (similar to MARINA and ANCHOR), $95 \%$ lost fewer than three lines of vision, and $35 \%$ gained three or more lines with a mean of 5.6 injections. ${ }^{32,36}$

The CATT study demonstrated that excellent results for visual acuity could be achieved with less-than-monthly regimens. ${ }^{25,29}$ The mean gain of 5.9 letters with bevacizumab when given as needed, and of 6.8 letters with ranibizumab when given as needed, are the best outcomes observed with less-than-monthly regimens. Ranibizumab given as needed was equivalent to ranibizumab given monthly. Bevacizumab given as needed was equivalent at all time points except at 52 weeks when the comparison was inconclusive. In view of these results, the importance of monthly visits and OCT imaging cannot be overemphasized.

A more individualized approach to treating CNV with anti-VEGF pharmacotherapy which is gaining popularity is 'treat and extend. ${ }^{\prime 33,37}$ A typical treat-and-extend regimen begins with monthly injections until the signs of subretinal exudation have resolved with confirmation by OCT. The treatment interval is then sequentially lengthened by one to two weeks as long as there are no signs of recurrent exudation. If recurrent exudation is detected on a follow-up visit, the treatment interval is reduced to the previous interval. Treatment is rendered at every visit but 
the time between visits is individualized based on the patient's response to treatment. This regimen allows maintaining an exudation-free macula with fewer injections. ${ }^{33,37}$ There have been individual favorable reports on applying double-dose anti-VEGF at monthly intervals, or applying a double-time dosing of a conventional dose at two-week intervals for non-responsive cases and for pigment epithelial detachments. ${ }^{34-36,38-40}$ Some patients treated with anti-VEGF pharmacotherapy for CNV experience a massive submacular hemorrhage when the treatment is stopped. One approach that may be helpful in preventing this complication is the treat-and-extend approach with intervals of no longer then three months. We still lack evidence-based recommendations regarding when to stop injecting anti-VEGF pharmacotherapy for the treatment of $\mathrm{CNV} .^{37,41}$ In an effort to reduce the number of injections while maintaining the therapeutic effect, combination treatments with PDT, steroids, or radiation have demonstrated some success. ${ }^{40,44}$

Figure 3 summarizes the four treatment regimens that are currently used in retina practices. It has also been suggested that repetitive injections of intravitreal anti-VEGF pharmacotherapy in patients with AMD result in a decrease in biological response (tachyphylaxis). ${ }^{44}$

\section{Summary and Future Developments}

The current delivery method of all anti-VEGF pharmacotherapy in the treatment of CNV is repetitive intravitreal injections. Although VEGF Trap-Eye shows some promise in requiring less frequent injections, many efforts are being made in search of a better, less invasive drug delivery method. Possible future systems may include local delivery as topical drops or long-acting, sustained-release vitreal implants.

Anti-VEGF pharmacotherapy has revolutionized the way we treat CNV. There are several molecular mechanisms that play a role in the development of CNV. These differ between disease etiology and even between subtypes of the same disease. Therefore, future combination therapies affecting multiple molecular mechanisms may be even more effective in the treatment of CNV. Despite the wide variety of anti-VEGF pharmacotherapies available today, there are still many challenges and unanswered questions regarding the determination of the optimal anti-VEGF pharmacotherapy agent, the best treatment regimen, the optimal dosage, the duration of treatment, and the route of administration. Future research and further clinical experience with the use of these agents will shed some light and hopefully clear up some of these unresolved dilemmas.
1. Gragoudas ES, Adamis AP, Cunningham ET Jr, et al., Pegaptanib for neovascular age-related macular degeneration, N Eng/ I Med, 2004;351:2805-16.

2. Argon laser photocoagulation for neovascular maculopathy. Five-year results from randomized clinical trials. Macular Photocoagulation Study Group, Arch Ophthalmol, 1991;109:1109-14

3. Bressler NM, Photodynamic therapy of subfoveal choroidal neovascularization in age-related macular degeneration with verteporfin: two-year results of 2 randomized clinical trials-tap report 2, Arch Ophthalmol, 2001:119:198-207.

4. Brown DM, Michels M, Kaiser PK, et al., Ranibizumab versus verteporfin photodynamic therapy for neovascular age-related macular degeneration: Two-year results of the ANCHOR study, Ophthalmology, 2009;116:57-65.

5. Heier JS, Boyer D, Nguyen QD, et al., The 1-year results of CLEAR-IT 2, a phase 2 study of vascular endothelial growth factor trap-eye dosed as-needed after 12-week fixed dosing, Ophthalmology, 2011;118:1098-106.

6. Rosenfeld PJ, Brown DM, Heier JS, et al., Ranibizumab for neovascular age-related macular degeneration, N Eng/ J Med, 2006;355:1419-31.

7. Penn JS, Madan A, Caldwell RB, et al., Vascular endothelial growth factor in eye disease, Prog Retin Eye Res, 2008;27:331-71.

8. Ferrara N, Gerber HP, LeCouter J, The biology of VEGF and its receptors, Nat Med, 2003;9:669-76.

9. Kliffen M, Sharma HS, Mooy CM, et al., Increased expression of angiogenic growth factors in age-related maculopathy, Br J Ophthalmol, 1997;81:154-62.

10. Campochiaro PA, Retinal and choroidal neovascularization, J Cell Physiol, 2000;184:301-10

11. West SK, Looking forward to 20/20: a focus on the epidemiology of eye diseases, Epidemiol Rev, 2000;22:64-70.

12. Schaal S, Tezel T, Differences in the Biological Responses of Subretinal Choroidal Neovascularization Subtypes to Intravitreal Anti-VEGF Pharmacotherapy, Presented at: 28th Annual Meeting of the American Society of Retina Specialists, Vancouver, Canada, 30 August 2010

13. Iacono P, Parodi MB, Papayannis A, et al., Intravitreal Bevacizumab Therapy on an As-per-needed Basis in Subfoveal Choroidal Neovascularization Secondary to Pathological Myopia: 2-Year Outcomes of a Prospective Case Series, Retina, 2011;31:1841-7.

14. Gulati N, Forooghian F, Lieberman R, Jabs DA, Vascular endothelial growth factor inhibition in uveitis: a systematic review, Br J Ophthalmol, 2011;95:162-5.

15. Artunay $\mathrm{O}$, Yuzbasioglu $\mathrm{E}$, Rasier $\mathrm{R}$, et al., Combination Treatment with Intravitreal Injection of Ranibizumab and Reduced Fluence Photodynamic Therapy for Choroidal Neovascularization Secondary to Angioid Streaks: Preliminary Clinical Results of 12-Month Follow-Up, Retina, 2011;31:1279-86.

16. Schaal S, Barr C, Kaplan H, Tezel T, Intravitreal Bevacizumab is Superior to Laser Photocoagulation in the Treatment of Juxtafoveal Choroidal Neovascularization Secondary to POHS, Presented at: Retina Congress, a combined meeting of the American Society of Retina Specialists, The Macula Society, and
The Retina Society, New York, NY, 4 October 2009.

77. Bressler NM, Arnold J, Benchaboune M, et al., Verteporfin therapy of subfoveal choroidal neovascularization in patients with age-related macular degeneration: additional information regarding baseline lesion composition's impact on vision outcomes-TAP report No. 3, Arch Ophthalmol, 2002;120:1443-54.

18. Argon laser photocoagulation for neovascular maculopathy. Five-year results from randomized clinical trials. Macular Photocoagulation Study Group, Arch Ophthalmol, 1991;109:1109-14.

19. Bressler NM, Bressler SB, Hawkins BS, et al., Submacular surgery trials randomized pilot trial of laser photocoagulation versus surgery for recurrent choroidal neovascularization secondary to age-related macular degeneration: I. Ophthalmic outcomes submacular surgery trials pilot study report number 1, Am I Ophthalmol, 2000;130:387-407.

20. Battaglia PM, lacono P, Verbraak FD, Bandello F, Antivascular endothelial growth factors for inflammatory chorioretinal disorders, Dev Ophthalmol, 2010;46:84-95.

21. Nielsen JS, Fick TA, Saggau DD, Barnes $\mathrm{CH}$, Intravitreal anti-vascular endothelial growth factor therapy for choroidal neovascularization secondary to ocular histoplasmosis syndrome, Retina, 2011;32(3):468-72.

22. Gragoudas ES, Adamis AP, Cunningham ET Jr, Pegaptanib for neovascular age-related macular degeneration, N Engl J Med 2004;351:2805-16

23. Brown DM, Michels M, Kaiser PK, et al., Ranibizumab versus verteporfin photodynamic therapy for neovascular age-related macular degeneration: Two-year results of the ANCHOR study, Ophthalmology, 2009:116:57-65.

24. Rosenfeld PJ, Brown DM, Heier JS, et al., Ranibizumab for neovascular age-related macular degeneration, N Eng/ J Med 2006;355:1419-31

25. Arevalo JF, Sanchez JG, Wu L, et al., Intravitreal bevacizumab for subfoveal choroidal neovascularization in age-related macular degeneration at twenty-four months: the Pan-American Collaborative Retina Study, Ophthalmology, 2010;117:1974-81.

26. Arevalo JF, Adan A, Berrocal MH, et al., Intravitreal bevacizumab for inflammatory choroidal neovascularization: results from the Pan-American Collaborative Retina Study Group at 24 months, Retina, 2011;31:353-63.

27. Bashshur ZF, Haddad ZA, Schakal AR, et al., Intravitreal bevacizumab for treatment of neovascular age-related macula degeneration: the second year of a prospective study, Am J Ophthalmol, 2009;148:59-65.

28. Brechner RJ, Rosenfeld PJ, Babish JD, Caplan S, Pharmacotherapy for neovascular age-related macular degeneration: an analysis of the $100 \% 2008$ medicare fee-forservice part B claims file, Am J Ophthalmol, 2011;151:887-95.

29. Martin DF, Maguire MG, Ying GS, et al., Ranibizumab and bevacizumab for neovascular age-related macular degeneration, N Engl J Med, 2011;364:1897-908.

30. Rakic JM, Lambert V, Devy L, et al., Placental growth factor, a member of the VEGF family, contributes to the development of choroidal neovascularization, Invest Ophthalmol Vis SCl, 2003:44:3186-93.

31. FDA, VEGF Trap-Eye (aflibercept ophthalmic solution) Briefing
Document. Available at: www.fda.gov/downloads/Advisory Committees/CommitteesMeetingMaterials/Drugs/ DermatologicandOphthalmicDrugsAdvisoryCommittee/ UCM259143.pdf (accessed September 3, 2012)

32. Regeneron Announces EYLEA ${ }^{T M}, 2011$. Available at: http://investor.regeneron.com/releasedetail.cfm?ReleaselD= 585837 (accessed September 3, 2012)

33. Patel JJ, Mendes MA, Bounthavong $\mathrm{M}$, et al., Cost-utility analysis of bevacizumab versus ranibizumab in neovascular age-related macular degeneration using a Markov model, J Eval Clin Pract, 2010;18(2):247-55

34. van der Reis MI, La Heij EC, De Jong-Hesse Y, et al., A systematic review of the adverse events of intravitrea anti-vascular endothelial growth factor injections, Retina, 2011;31:1449-69.

35. Regillo $C D$, Brown DM, Abraham P, et al. Randomized, double-masked, sham-controlled trial of ranibizumab for neovascular age-related macular degeneration: PIER Study year 1, Am J Ophthalmol, 2008;145:239-48.

36. Lalwani $G A$, Rosenfeld PJ, Fung AE, et al., A variable-dosing regimen with intravitreal ranibizumab for neovascular age-related macular degeneration: year 2 of the PrONTO Study, Am I Ophthalmol, 2009:148:43-58.

37. Gupta OP, Shienbaum G, Patel AH, et al., A treat and extend regimen using ranibizumab for neovascular age-related macular degeneration clinical and economic impact, Ophthalmology, 2010;117:2134-40.

38. Chen C, Double-dose Ranibizumab For Choroida Neovascularization Association With Age-related Macular Degeneration Minimally Responsive To Prior anti $\alpha$-VEGF Treatment, Presented at: American Society of Retina Specialists 29th Annual Meeting, Boston, MA, US, August 2011.

39. Chan CK, Management of Vascularized Pigment Epithelial Detachments Due to AMD with High (2.0 MG) vs. Conventionaldose $(0.5 \mathrm{MG})$, Ranibizumab, Presented at: American Society of Retina Specialists 29th Annual Meeting, Boston, MA, US, August 2011

40. Nielsen JS, Increased Dose Ranibizumab for Persistent Choroida Neovascular Activity in Neovascular Age-related Macular Degeneration, Presented at: American Society of Retina Specialists 29th Annual Meeting, Boston, MA, US, August 2011.

41. Gaudric A, Cohen SY, when should anti-vascular endothelial growth factor treatment be stopped in age-related macular degeneration?, Am J Ophthalmol, 2010;149:4-6.

42. Couch SM, Bakri SJ, Review of combination therapies for neovascular age-related macular degeneration, Semin Ophthalmol, 2011;26:114-20

43. Avila MP, Farah ME, Santos A, et al., Three-year safety and visual acuity results of epimacular 90strontium/90yttrium brachytherapy with bevacizumab for the treatment of subfoveal choroidal neovascularization secondary to age-related macualr degeneration, Retina, 2011;32(1):10-8.

44. Schaal S, Kaplan HJ, Tezel TH, Is there tachyphylaxis to intravitreal anti-vascular endothelial growth factor pharmacotherapy in age-related macular degeneration? Ophthalmology, 2008;115:2199-205. 